2. Bộ y tế-Vskbmt. Kễ hoạch hành động quốc gia dự phòng và kiểm soát ưng thư cổ tư cung giai đoan 2016-2025. 2016.

3. Lê Quang Vinh LTH. Phát hiện tỉ lệ nhiễm HPV và tế bào cổ tử cung bất thường ở phụ nữ Thái Nguyên. Tạp chí nghiên cứu y học. 2013:3. 3.

4. Trương Quang Vinh. Nghiên cứu nhiểm Human Papilloma virus ở các phụ nữ có các tổn thương tiền ung thư và ung thư cổ tử cung, . Trường Đại hoc Y Dước, Đai hoc Huế. 2010.

5. J. Thomas Cox MPEC, PhD, MPH; Catherine M. Behrens, MD, PhD; Abha Sharma, PhD;Thomas C. Wright Jr, MD; Jack Cuzick, PhD;. and the Athena HPV Study Group, (2012), Comparison of cervical cancer screening strategies incorporating different combinations of cytology, HPV testing, and genotyping for HPV 16/18: results from the ATHENA HPV study. American Journal of Obstetrics and Gynecology 2012.

6. Phạm Thị Ngọc Xuấn TTL. Tầm soát ung thư cổ tử cung tại các xã huyên Thủ Thửa tỉnh Long An. Tạp chí y học thành phổ Hồ Chí Minh. 2008;1:12.

7. NatachaPhoolcharoen $\mathbf{N}$, ThaniyaSricharunrat, SiripornSaeloo, WaraphornKrongthong (2017). A population-based study of cervical cytology findings and human papillomavirus infection in a suburban area of Thailand. Gynocologic oncology report. 2017:21:73.

8. Nguyến Thị Hồng Nga. Khảo sát mối liên quan giữa nhiễm HPV nguy cơ cao với các tổn thương tiền ung thư và ung thư cổ tử cung tai bênh viện phụ sản trung ương. Đại học Y Hà Nội 2017.

\title{
ĐÁNH GIÁ KẾT QUẢ TAOO HİNH HỆ THỐNG XƯƠNG CON VÀ TẠO HİNH MÀNG NHĨ BẰNG SỤN TRÊN BỆNH NHÂN VIÊM TAI DÍNH
}

\section{TÓM TẮT}

Sử dụng phương pháp mô tả từng trường hợp có can thiệp nhằm đánh giá kết quả sau tạo hình hệ thống xương con và phục hồi màng nhĩ bằng sụn. Kết quả: Tuổi thường gặp 40,06 \pm 11.06 tuổi. Nữ nhiều hơn nam. Triêu chứng cơ năng thường găp ù tai, nghe kém. Nội soi tai $50 \%$ viêm tai dính toà̃n bộ, $50 \%$ viêm tai dính khu trú. Thính lực trước phẫu thuật ngưỡng nghe đường xương là 15,78 $\pm 12,50 \mathrm{~dB}$, PTA trung bình trước phẫu thuất là $43,36 \pm 17,45 \mathrm{~dB}$, chỉ số $\mathrm{ABG}$ trước phẫu thuật là $27,65 \pm 13,71 \mathrm{~dB}$. Chụp cắt lớp vi tính chuỗi xương con liên tục ở 10/16 BN chiếm $62,5 \%$, chuỗi xương con bị gián đoạn ở 6/16 BN chiếm $37,5 \%$. Tổn thương xương con trong viêm tai dính: $100 \%$ tổn thương xương đe, $31,25 \%$ tổn thương cả hỗn hợp búa đe, không có trường hợp nào tổn thương cả 3 xương con. Phục hồi màng nhĩ bằng sụn và màng sụn trong $81,25 \%$, kết hợp sụn và cân cơ thái dương trong $18,75 \%$ trường hợp. Thời gian theo dõi trung bình sau phẫu thuật là $9,6 \pm 7,2$ tháng. Sau mổ $75 \%$ cải thiện tình trạng ù tai và nghe kém. Ngưỡng nghe đường khí trung bình sau phẫu thuật là $33,59 \pm 14,90 \mathrm{~dB}$, chỉ số $\mathrm{ABG}$ sau phẫu thuât là 23,98 $\pm 14,3 \mathrm{~dB}$. Kết luận: Phẫu thuật tạo hình hệ thống xương con và phục hồi màng nhĩ bằng sụn là phương pháp căn bản điều trị viêm tai dính và tái tạo chức năng nghe. sụn

Tư khóa: viêm tai dính, phục hồi màng nhĩ bằng

\footnotetext{
${ }^{1}$ Bệnh viện Đa khoa Đông Anh

${ }^{2}$ Trường Đại học Y Hà Nội

Chiu trách nhiệm chính: Trịnh Đắc Chung

Email: trinhdacchung@gmail.com

Ngày nhận bài: 13.9.2021

Ngày phản biên khoa họ: 10.11.2021

Ngày duyệt bài: 17.11.2021
}

\section{Trịnh Đắc Chung ${ }^{1}$, Nguyễn Thị Tố Uyên ${ }^{2}$}

\section{SUMMARY}

ASSESSMENT OF THE RESULTS OF OSSICULAR CHAIN RECONSTRUCTION AND CARTILAGE TYMPANOPLASTY IN PATIENTS WITH ADHESIVE OTITIS MEDIA

Using a descriptive case-by-case approach to evaluation of the results of ossicular chain reconstruction and cartilage tympanoplasty. Results: Most patients are at the age of $40.06 \pm 11.06$. Females account for a larger proportion. Symptoms are often tinnitus, hearing loss. Otoscopy results show $50 \%$ of patients having total adhesive otitis media, 50\% others having focal adhesive otitis media. Preoperative hearing threshold is $15.78 \pm 12.50 \mathrm{~dB}$, average PTA before surgery is $43.36 \pm 17.45 \mathrm{~dB}$, preoperative $A B G$ is $27.65 \pm 13.71 \mathrm{~dB}$. Computed tomography shows 10/16 patients, accounting for $62.5 \%$ have continuous ossicular chain, and 6/16 patients accounting for $37.5 \%$ have broken chain. Injury to the ossicles in adhesive otitis media: $100 \%$ of patients have damaged anvils, $31.25 \%$ others have damaged hammer and anvil, no cases have all 3 bones damaged. Cartilage tympanoplasty are applied in $81.25 \%$ of patients, $18.75 \%$ are treated with cartilage and temporomandibular fascia. The mean follow-up time is $9.6 \pm 7.2$ months. After surgery, tinnitus and hearing loss are relieved in $75 \%$ of patients. The mean airway threshold after surgery is $33.59 \pm 14.90 \mathrm{~dB}$, and $A B G$ after surgery is $23.98 \pm 14.3 \mathrm{~dB}$.

Keywords. adhesive otitis media, cartilage tympanoplasty.

\section{I. ĐĂT VẤN ĐỀ}

Viêm tai dính là hiện tượng màng nhĩ bị hút và dính vào thành trong hòm nhĩ và chuỗi xương con. Phẫu thuật tạo hình hệ thống xương con và phục hồi màng nhĩ là phương pháp căn bản để điều trị viêm tai dính, và tái tạo lại chức năng 
nghe. Nhiêu chất liệu được sử dụng để tạo hình màng nhĩ như cân cơ, da, tĩnh mạch, màng sụn và sụn. Trong đó chất liệu sụn ngày càng được quan tâm nhiều, ở những trường hợp có nguy cơ tái phát viêm tai dính, hoặc để gia cố vật liệu thay thế xương con. Do vậy chúng tôi tiến hành nghiên cứu này với mục tiêu: Đánh giá kết quả sau tạo hình hệ thống xương con và phục hồi màng nhĩ bằng sụn.

\section{II. ĐỐI TƯợNG VÀ PHƯƠNG PHÁP NGHIÊN CỨU}

Đối tượng nghiên cứu: nghiên cứu mô tả 15 BN viêm tai dính với 16 tai được phẫu thuật tạo hình hệ thống xương con và phục hồi màng nhĩ bằng sụn tại bệnh viện Tai Mũi Họng Trung Ương từ 1/2019 đến tháng 7/2021. Các bệnh nhân được làm hồ sơ bệnh án đây đủ, được khám nội soi tai mũi họng, chụp cắt lớp vi tính xưỡng thái dương, có kết quả đo thính lực trước phẫu thuật và sau phẫu thuật ít nhất 6 tuân

Thiết kế nghiên cứu: nghiên cứu mô tả từng trường hợp có can thiệp

Phương pháp xử lý số liệu: các số liệu thu được qua bệnh án nghiên cứu được xử lý trên phần mềm thống kê y học SPSS 20.0.

\section{KẾT QUẢ NGHIÊN CỨU}

Giới: nữ nhiêuu hơn nam với tỷ lệ 9/15(60\%) và 6/15 (40\%).

Tuổi: độ tuổi trung bình là 40.06 × 11.6 tuổi.

Đặc điểm lâm sàng cận lâm sàng viêm tai dính có tổn thương xương con

- Cơ năng

Bảng 3.1. Triêuu chứng cơ năng

Biểu hiện Số bệnh nhân (n) Tỷ lệ (\%)

\begin{tabular}{|c|c|c|}
\hline Ù tai & 16 & 100 \\
\hline Nghe kém & 12 & 75 \\
\hline Chảy tai & 6 & 37,5 \\
\hline
\end{tabular}

Ú tai là triệu chứng hay gặp nhất $100 \%$ các trường hợp.

Nghe kém cũng gặp ở 75\% trường hợp.

- Nôi soi tai: Có 8 trường hợp viêm tai dính toàn bộ chiếm $50 \%, 8$ trường hợp viêm tai dính khu trú chiếm $50 \%$.

- Chụp cắt lớp vi tính. Trên hình ảnh cắt lớp vi tính xương thái dương:

Chuỗi xương con liên tục ở 10/16 BN chiếm 62,5\%.

Chuỗi xương con gián đoạn ở 6/16 BN chiếm $37,5 \%$.

- Thính lực trước phẫu thuật

\section{Bảng 3.2. Thính lực trước phẫu thuật ở từng tần số}

\begin{tabular}{|c|c|c|c|c|c|}
\hline $\begin{array}{l}\text { Tân số } \\
\text { NN (dB) }\end{array}$ & $500 \mathrm{~Hz}$ & $1000 \mathrm{~Hz}$ & 200 & 40 & Trur \\
\hline $\mathrm{DX}(\mathrm{N}=16)$ & $11,56 \pm 7,40$ & $11,87 \pm 10,78$ & $17,18 \pm 12,64$ & $22,50 \pm 15,49$ & $15,78 \pm 12,50$ \\
\hline PTA $(\mathrm{N}=16)$ & $43,43 \pm 15,24$ & $41,56 \pm 17,19$ & $39,37 \pm 18,40$ & $49,06 \pm 19,08$ & $43,36 \pm 17,45$ \\
\hline ABG $(N=16)$ & $31,87 \pm 15,26$ & $29,69 \pm 13,78$ & $22,19 \pm 11,10$ & $26,56 \pm 13,62$ & $27,65 \pm 13,71$ \\
\hline
\end{tabular}

Ngưỡng nghe đường xương trước phẫu thuật

là $15,78 \pm 12,50 \mathrm{~dB}$.

Ngưỡng nghe đường khí trước phẫu thuật là $43,36 \pm 17,45 \mathrm{~dB}$.

Chỉ số ABG trước phẫu thuật trong nghiên cứu của chúng tôi là $27,65 \pm 13,71 \mathrm{~dB}$.

- Tổn thương xương con

Tất cả các trường hợp đều có tổn thương xương đe.

Tổn thương hỗn hợp búa đe trong 5/16 trường hợp chiếm 31,25\%

Tổn thương đơn độc xương đe chiếm 11/16 trường hợp chiếm 68,75\%

Đánh giá kết quả sau tạo hình hệ thống xương con và phục hồi màng nhĩ bằng sụn.

Thời gian theo dõi sau phẫu thuật

Thời gian theo dõi trung bình sau phẫu thuật là 9,6 \pm 7,2 tháng

Triệu chứng cơ năng

$75 \%$ trường hợp sau mổ BN đõ ù tai, $75 \%$ trường hợp BN cải thiện sức nghe. Kết quả phục hồi về giải phẫu

100\% màng nhĩ được vá kín.

Kết quả phục hồi về thính lực

Bảng 3.3. Ngưỡng nghe đường xương trước và sau phẫu thuật ở từng tần số

\begin{tabular}{|c|c|c|c|c|c|}
\hline ĐX (dB) & $500 \mathrm{~Hz}$ & $1000 \mathrm{~Hz}$ & $2000 \mathrm{~Hz}$ & $4000 \mathrm{~Hz}$ & Trung bình \\
\hline Trước PT & 11 & $11, \varepsilon$ & $17,18 \pm 12,64$ & $22,5 \pm$ & 12,50 \\
\hline Sau PT & $6,25 \pm 8,06$ & $4,06 \pm 8,98$ & $10 \pm 11,4$ & $18,12 \pm 15,26$ & $9,60 \pm 12,25$ \\
\hline Hiệu số & $4,68 \pm 9,21$ & $7,81 \pm 8,15$ & $7,18 \pm 11,96$ & $4,37 \pm 10,30$ & $6,01 \pm 9,88$ \\
\hline
\end{tabular}

Bảng 3.4. Ngưỡng nghe đường khí trước và sau phấu thuật ở từng tần số

\begin{tabular}{|c|c|c|c|c|c|}
\hline Tân số & $\mathbf{5 0 0} \mathbf{~ H z}$ & $\mathbf{1 0 0 0} \mathbf{~ H z}$ & $\mathbf{2 0 0 0} \mathbf{~ H z}$ & $\mathbf{4 0 0 0} \mathbf{~ H z}$ & Trung bình \\
\hline PTA (dB) & $43,43 \pm 15,24$ & $41,56 \pm 17,19$ & $39,37 \pm 18,24$ & $49,06 \pm 19,08$ & $43,36 \pm 17,5$ \\
\hline Trước PT & 43,06 &
\end{tabular}




\begin{tabular}{|c|c|c|c|c|c|c|c|c|}
\hline Sau PT & \multicolumn{2}{|c|}{$34,37 \pm 12,76$} & \multicolumn{2}{|c|}{$32,5 \pm 12,78$} & \multicolumn{2}{|c|}{$30,93 \pm 14,28$} & $36,56 \pm 16,9$ & $33,59 \pm 14,90$ \\
\hline Hiệu quả & 9,06 & $\pm 10,83$ & & $6 \pm 10,68$ & & $43 \pm 12,07$ & $12,50 \pm 19,66$ & $9,76 \pm 13,58$ \\
\hline \multicolumn{9}{|c|}{ Bảng 3.5. Chi số ABG trước và sau phấu thuật ở từng tần số } \\
\hline \multicolumn{2}{|c|}{ ABG (dB) Tân số } & \multicolumn{2}{|c|}{$500 \mathrm{~Hz}$} & \multicolumn{2}{|c|}{$1000 \mathrm{~Hz}$} & $2000 \mathrm{~Hz}$ & $4000 \mathrm{~Hz}$ & Trung bình \\
\hline \multicolumn{2}{|c|}{ Trước PT } & \multirow{2}{*}{\multicolumn{2}{|c|}{$\begin{array}{l}31,87 \pm 15,26 \\
28,12 \pm 13,88\end{array}$}} & \multicolumn{2}{|c|}{$29,69 \pm 13,78$} & $\pm 11,1$ & $26,56 \pm 13,62$ & $27,65 \pm 13,10$ \\
\hline \multicolumn{2}{|c|}{ Sau PT } & & & \multirow{2}{*}{\multicolumn{2}{|c|}{$\begin{array}{r}28,4 \pm 13,25 \\
1,56 \pm 10,28\end{array}$}} & $20,93 \pm 14,96$ & $18,43 \pm 12,34$ & $23,98 \pm 14,30$ \\
\hline \multicolumn{2}{|c|}{$\begin{array}{l}\text { Hiệu quả ABG thu } \\
\text { được sau phẫu thuật }\end{array}$} & \multicolumn{2}{|c|}{$3.75 \pm 12.71$} & & & 8 & $8.12 \pm 17,21$ & $3,67 \pm$ \\
\hline
\end{tabular}

\section{BÀN LUẬN}

Giới: Trong nghiên cứu của chúng tôi tỷ lệ nữ nhiều hơn nam, tuy nhiên nghiên cứu này thực hiện với lượng bệnh nhân ít, tại một bệnh viện nên không có giá trị đại diện cho quần thể lớn.

Tuổi: Độ tuổi trung bình của nghiên cứu là 40.6 × 11.6 tuổi cao hớn của các nghiên cứu của các tác giả Đào Trung Dũng ${ }^{1}$, Khiếu Hữu Thanh ${ }^{2}$ tương tự với nghiên cứu của Keiichi Ichimura ${ }^{5}$

\section{Đặc điểm lâm sàng:}

Triệu chứng cơ năng: hay gặp là ù tai (16/16) bệnh nhân tỷ lệ này cao hơn các nghiên cứu của Đào Trung Dũ̃ng ${ }^{1}$, Khiếu Hữu Thanh ${ }^{1}$. Trong nghiên cứu của Yu-mei Shen ${ }^{8}$ tỉ lệ ù tai là $66,66 \%$. Đây là triệu chứng chủ quan của người bênh có thể bi ảnh hưởng bởi nhiều yếu tố như tầm lý, thể lực. Nghe kém ở 12/16 BN chiếm $75 \%$, tỉ lệ này thấp hơn trong các nghiên cứu của Đào Trung Dũng ${ }^{1}$, Khiếu Hữu Thanh ${ }^{2}$.

Nôi soi tai: Có 8 trường hợp viêm tai dính toàn bộ chiếm $50 \%, 8$ trường hợp viêm tai dính khu trú $50 \%$, kết quả này khác với nghiên cứu của Cao Minh Thành ${ }^{3}$ là viêm tai dính khu trú là $75,5 \%$ và viêm tai dính toàn bộ là $24,5 \%$

Thính lực bệnh nhân trước phấu thuật

Ngưỡng nghe đường xương trước phẫu thuật là $15,78 \pm 12,5 \mathrm{~dB}$.

Ngưỡng nghe đường khí trước phẫu thuật là $43,36 \pm 17,45 \mathrm{~dB}$.

Chỉ số ABG trước phẫu thuật là $27,65 \pm 13,71 \mathrm{~dB}$.

Trong nghiên cứu của Cao Minh Thành ${ }^{3}$ PTA trước phẫu thuât là $46,5 \pm 15,5 \mathrm{~dB}, \mathrm{ABG}$ trước phẫu thuật là $39,7 \pm 11,3 \mathrm{~dB}$.

Ngưỡng nghe trung bình đường khí trong nghiên cứu này cũng tương tự như trong nghiên cứu của Wenquan $\mathrm{Li}^{7}$, khoảng cách đường khí đường xương cũng tương tự của nghiên cứu của Aisha Larem 6 .

\section{Chụp cắt lớp vi tính}

Trên hình ảnh cắt lớp vi tính xương thái dương:

Chuỗi xương con liên tục ở 10/16 BN chiếm $62,5 \%$.

Chuỗi xương con gián đoạn ở 6/16 BN chiếm $37,5 \%$.
Tổn thương xương con. 100\% tổn thương xương đe, kết quả này cũng phù hợp với nghiên cứu của Cao Minh Thành ${ }^{3}$

Đánh giá kết quả tạo hình hệ thống xương con và phục hồi màng nhĩ bằng sụn trên bệnh nhân viêm tai dính

Thời gian theo dõi sau phẫu thuật

Thời gian theo dõi trung bình sau phẫu thuật là $9,6 \pm 7,2$ tháng.

Cơ năng: sau mổ $75 \%$ cải thiện sức nghe, $75 \%$ trường hợp thấy đõ ù tai, kết quả này cũng phù hợp với nghiên cứu của Wenquan Li là $80 \%$.

Kết quả phục hồi màng nhĩ: 100\% màng nhî được vá kín,

Kết quả này cũng tương tự như trong nghiên cứu của Aisha Larem ${ }^{6}$ màng nhĩ được vá kín ở tất cả các trường hợp, trong nghiên cứu của Yu-mei Shen ${ }^{8}$ màng nhĩ được vá kín trong 17/18 trường hợp.

Kết quả phục hồi thính lực. Ngưỡng nghe đường xương sau phẫu thuật là 9,60 $\pm 12,25 \mathrm{~dB}$.

Ngưỡng nghe đường khí trung bình trước phẫu thuật là $43,36 \pm 17,5 \mathrm{~dB}$ và ngưỡng nghe đường khí trung bình sau phẫu thuật là 33,59 \pm 14,9 .

PTA sau phẫu thuật tăng 9,6 dB, trong nghiên cứu của Cao Minh Thành ${ }^{3}$ PTA sau phầu thuật tăng $11,7 \mathrm{~dB}$.

Ngưỡng nghe đường khí trước phẫu thuât trong nghiên cứu của Wenquan Li $\mathrm{Li}^{7} 31,7 \pm 12,3 \mathrm{~dB}$.

Chỉ số $A B G$ trước và sau phẫu thuật lần lượt là $26,65 \pm 13,1 \mathrm{~dB}$ và $23,98 \pm 14,3 \mathrm{~dB}$, trong nghiên cứu của Cao Minh Thành ${ }^{3} A B G$ sau phẫu thuật tăng $11.8 \mathrm{~dB}$.

\section{KẾT LUẬN}

Phẫu thuật tạo hình hệ thống xương con và phục hồi màng nhĩ bằng sụn là phương pháp căn bản điều trị viêm tai dính và tái tạo chức năng nghe.

\section{TÀI LIỆU THAM KHẢO}

1. Đào Trung Dũng (2007), "Đánh giá kết quả điều trị xẹp nhĩ", luận văn tốt nghiệp bác sĩ nội trú, Đai hoc Y Hà Nối.

2. Khiếu Hữu Thanh (2012), "Nghiên cứu chức năng tai giữa trong các giai đoạn của xẹp nhĩ qua 
thính lực và nhĩ lượng", Luận văn thạc sĩ y học, Đại hoc Y Hà Nôi.

3. Cao Minh Thành (2012), "Viêm tai dính: phân loại và xử trí", Tổng hội Y học Việt Nam, Volume (57-8) 81-87.

4. Nguyển Lễ̂ Thủy (2015), "Hình thái lâm sàng của xẹp nhî̃ qua nội soi tại bệnh viện trường đại học Y Thái Nguyên", Tạp chí khoa học và công nghệ, 134(04), 163-168.

5. Keiichi Ichimura, Kotaro Ishikawa, Ken-ichi Nakamura, Chizu Saito (2009), "Cartilage palisade tympanoplasty for adhesive otitis media", Nihon Jibiinkoka Gakkai Kaiho, 112(6): 474-9.
6. Aisha Larem, Hassan Haidar (2016), "Tympanoplasty in adhesive otitis media: A descriptive study", Epub, 126(12), 2804-2810.

7. Wenquan Li, Qiang Du, Wuqing Wang (2019), "Treatment of adhesive otitis media by tympanoplasty combined with fascia grafting catheterization", Epub, 276(10), 2721-2727.

8. Yu-mei Shen, Wen-qing Sun, Hong Shen, Yong-he Li (2010), "Tragus cartilage tympanoplasty for treatment of adhesive otitis media", Journal of Southern Medical University, 30(6): $1382-4$.

\section{NGHIÊN CỨU TIỀN SỬ VIÊM NHIỄM ĐƯỜNG SINH DỤC VÀ MộT Số YẾU TỐ LIÊN QUAN ĐẾN VÔ SINH THỨ PHÁT DO TẮC VÒI TỬ CUNG TẠI BỆNH VIỆN PHỤ SẢN TRUNG ƯƠ'NG NĂM 2017}

\section{TÓM TẮT}

Muc tiêu: Nghiên cứu tiền sử viêm nhiễm đường sinh dục và một số yếu tố liên quan đến vô sinh thứ phát do tắc vòi tử cung tại Bệnh viện Phụ sản Trung ương năm 2017. Đối tượng, phương pháp: Nghiên cứu hồi cứu trên 177 bểnh nhân được chẩn đoán vô sinh thứ phát do vòi tử cung được chỉ định phâuu thuật nội soi điêu trị (bao gồm cả bệnh nhân được chẩn đoán tắc vòi tử cung hoặc các bệnh lý khác của vòi tử cung nhưng không gây tắc vòi tử cung), có bệnh án đầy đủ thông tin tại Bệnh viện Phụ sản Trung ương từ tháng 1/2017 đến tháng 12/2017. Kết quả: Tỷ lệ bệnh nhân tắc vòi tử cung có tiền sử viêm âm đạo là 60,8\%; bệnh nhân tắc vòi tữ cung ở nhóm không có tiền sử viêm âm đạo là 40,2\% ( $p<0,05)$. Tỷ lệ bệnh nhân có các tiền sử liển quan ở nhóm bị tắc vòi tử cung lần lượt là: nhiễm Chlamydia (bi tắc vòi tử cung $72,7 \%$ ); đăt dụng cu tử cung (bị tắc vòi tử cung 68,6\%); phẫu thuật phụ khoa (bị tắc vòi tử cung 74,4\%); phá thai (bị tắc vòi tử cung $48,7 \%$ ); dùng thuốc tránh thai (bị tắc vòi tử cung 40\%). Kết luận: Tiền sử viêm nhiếm đường sinh dục dưới, tiền sử nhiễm Chlamydia và các tiền sử: đặt dụng cu tứ cung, phẫu thuât phu khoa vùng tiểu khung có liển quan đến vô sinh thứ phát do tắc vòi tử cung ở các bệnh nhân điều trị tại Bệnh viện Phụ sản Trung ương nằm 2017.

Tư khóa:Tiền sử liên quan, viêm nhiễm đường sinh dục, vô sinh thứ phát, tắc vòi tử cung.

\section{SUMMARY \\ ASSOCIATION BETWEEN SECONDARY}

\footnotetext{
*Bệnh viện Phụ sản Hà Nội

**Bệnh viện Phụ sản Trung ương

Chịu trách nhiệm chính: Nguyễn Duy Ánh

Email: bsanhbnhn@yahoo.com

Ngày nhận bài: 14.9.2021

Ngày phản biên khoa họ: 10.11.2021

Ngày duyệt bài: 18.11.2021
}

\section{Nguyễn Duy Ánh*, Vũ Văn Du** \\ INFERTILITY DUE TO FALLOPIAN TUBE OBSTRUCTION AND HISTORY OF GENITAL INFECTIONS AND OTHER FACTORS AT HANOI OBSTETRICS AND GYNECOLOGY HOSPITAL IN 2017}

Objectives: The study evaluated the association between secondary infertility due to fallopian tube obstruction and history of genital infections and other factors at Hanoi Obstetrics and Gynecology Hospital in 2017. Methods: Our cross-sectionsal study selected 177 patients with secondary infertility due to fallopian tube obstruction and other fallopian tube pathology. These patients were assigned to laparoscopy recanalization at Hanoi Obstetrics and Gynecology Hospital from 01/2017 to 12/2017. Results: 60,8 percent of patients with fallopian tube obstruction had prior vaginal infections $(p<0,05)$. We found other related history such as: $72,7 \%$ of patients with Chlamydia trachomatis infections had fallopian tube obstruction, $68,6 \%$ of patients using intrauterine devices, $74,4 \%$ of patients having prior pelvic surgery, $48,7 \%$ of patients used to have induced abortion, $40 \%$ of patients taking contraceptives. Conclusion: Secondary infertility due to fallopian tube obstruction in patients treated at Hanoi Obstetrics and Gynecology Hospital in 2017 is related to history of lower genital tract infections, Chlamydia trachomonas infection, prior pelvic surgery and using intrauterine devices.

Keyword: secondary infertility, fallopian tube obstruction, genital infections, related history.

\section{I. ĐẶT VẤN ĐỀ}

Vô sinh thứ phát là bệnh lý phổ biến trong sản phụ khoa hiện nay, nó gây ảnh hưởng lớn đến sức khỏe sinh sản và chất lượng cuộc sống của nhiều cặp vợ chồng. Trong đó, vô sinh do bệnh lý vòi tử cung là nguyên nhân thường gặp nhất chiếm $25-35 \%$ số trường hợp. Viêm nhiễm đường sinh dục là một trong các nguyên 